Rev. Adm. Saúde - Vol. 18, № 72, jul. - set. 2018

http://dx.doi.org/10.23973/ras.72.127

RELATO DE CASO

\title{
Mapeamento de processos na dispensação de medicamentos: ferramenta para gestão e melhoria da qualidade
}

Mapping of processes as an organizational model: intervention proposals in teaching-service interaction

Josué Souza Gleriano ${ }^{1}$, Sandiely Cristina Ribeiro Roela², Liz Vanessa Lupi Gasparini $^{3}$, Rita de Cássia Pessoa Bento ${ }^{4}$, Fabiana Cristina Furquim 5 , Verônica Modolo Teixeira ${ }^{6}$, Gisele Caroline Richi Fabro ${ }^{7}$

1. Enfermeiro, mestre em saúde pública. Docente da Universidade do Estado do Mato Grosso (UNEMAT), Tangará da Serra MT.

2. Enfermeira. Afiliada a UNEMAT, Tangará da Serra MT.

3. Administradora. Docente em administração pela UNEMAT, Tangará da Serra MT.

4. Enfermeira. Responsável pelo Serviço de Enfermagem do Hospital Municipal Arlete Daisy Chichetti de Brito, Tangará da Serra MT.

5. Farmacêutica. Responsável pelo Serviço de Fármácia do Hospital Municipal Arlete Daisy Chichetti de Brito, Tangará da Serra MT.

6. Enfermeira. Mestranda da Escola de Enfermagem de Ribeirão preto da USP, Ribeirão Preto SP.

7. Enfermeira. Mestranda da Escola de Enfermagem de Ribeirão preto da USP, Ribeirão Preto SP.

\section{RESUMO}

Trata-se de um relato de experiência com objetivo de apresentar o mapeamento e análise do fluxo de medicamentos em uma Unidade de Pronto Atendimento (UPA) da região sudoeste do estado de Mato Grosso MT, construído na integração ensino com a gestão administrativa do serviço, no ano de 2017. A equipe integrou profissionais da UPA, da farmácia, docentes do curso de administração e enfermagem e discentes dos respectivos cursos. Para mapear os processos definiram-se dois momentos: o primeiro construiu 0 
desenho de fluxo dos medicamentos, o levantamento das coletas de documentos e o segundo a verificação na prática. A análise dos dados resultou no delineamento do fluxo de medicamentos da farmácia do hospital para a UPA, modelo descritivo e fluxograma, que comparado com as normatizações direcionou um relatório sobre pontos de melhorias quanto ao planejamento logístico, reestruturação organizacional e sistema de informatização que carece de instrumentos que poderiam otimizar o tempo, a informação, a logística e a tomada de decisão no trabalho. A experiência permitiu conhecer as peculiaridades e aproximou os atores em uma reflexão-ação-reflexão da prática, além de possibilitar a formalização desse fluxo.

Palavras-chave: Administração hospitalar, fluxo de trabalho, medicamentos, organização.

\section{ABSTRACT}

This is an experience report with the objective of presenting the mapping and analysis of the drug flow in an Emergency Care Unit (UPA) in the southwest region of the state of Mato Grosso - MT, built in the integration of teaching with the administrative management of the service, in the year 2017. The team integrated professionals from the UPA, from the pharmacy, teaching staff of the courses of administration and nursing and students of the respective courses. In order to map the processes, two moments were defined: the first one built the design of the flow of medicines and the survey of the documents collections, and, the second, the verification in practice. The analysis of the data resulted in the design of the drug flow from the hospital pharmacy to the UPA, a descriptive model and flowchart, which compared with the regulations, directed a report about improvement points regarding logistical planning, organizational restructuring and computerization system that lacks instruments that could optimize time, information, logistics and decision making at work. The experience allowed to know the peculiarities and approached the actors in a reflection-action-reflection of the practice, besides making possible the formalization of this flow.

Keywords: Hospital administration, workflow, drugs, organization.

\section{INTRODUÇÃO}

O setor hospitalar é complexo e de difícil gerenciamento(1), principalmente na articulação de integrar os processos à logística hospitalar. No caso brasileiro, os hospitais de pequeno e médio porte são considerados pouco eficientes, e 
quando aplicados à visão baseada em recursos, que propõe uma vantagem competitiva sustentada e consequente desempenho superior ao dos concorrentes, esses hospitais carecem na construção de recursos internos o que resulta em baixa operacionalidade em função da análise dos seus processos $^{(2)}$.

Dada a importância de estudar o setor saúde, conhecido, em geral, por ser um late adopter ${ }^{(3)}$ do conhecimento gerencial nas suas organizações, em especifico os recursos de materiais e medicamentos, tanto o setor público e privado, há necessidade de controle do consumo e os custos dos seus serviços $^{(4)}$. Nas organizações do setor público, que possuem orçamentos restritos o controle do consumo e de custos, é imprescindível para que não privem funcionários e pacientes dos medicamentos necessários ao cuidado( ${ }^{(5-7)}$.

No ambiente hospitalar os processos que os medicamentos percorrem desde 0 recebimento até chegar à assistência ao paciente desempenha um papel importante, de modo que, a gestão administrativa hospitalar precisa analisar os processos do fluxo de medicamentos, no intuito de conservar os procedimentos ao menor custo possível e de maneira que a prestação de seus serviços não sofra interrupções prejudiciais aos pacientes, garantindo assim, a qualidade no suprimento dos medicamentos nas organizações hospitalares ${ }^{(7-10)}$.

A gestão de medicamentos é essencial na execução e controle de um processo de planejamento de suprimento hospitalar. Nos últimos anos, têm-se enfrentando problemas a partir de diversas situações como na execução administrativa do fluxo de medicamentos. Essa análise deriva-se da complexidade do serviço que necessita operacionalizar e padronizar os processos adequados para o fluxo de medicamentos, mas que enfrenta uma dinâmica, muitas vezes, inapropriada para a execução correta dos seus processos $^{(5,11)}$.

Em busca de propostas para apresentar ao setor de gestão de medicamentos, e a partir da necessidade de descrever processos e fluxos, a Política Nacional de Saúde contribui ao afirmar que é essencial a elaboração de protocolos, manuais e normativas com base nos princípios e diretrizes do Sistema Único de Saúde (SUS), a fim de subsidiar informações para a Política Nacional de Medicamentos na organização de fluxo de medicamentos, constituindo um dos elementos fundamentais para a efetiva implementação de ações, capazes de promover a melhoria das condições da assistência à saúde da população, garantindo a necessária segurança, eficácia e qualidade dos medicamentos ${ }^{(12)}$.

Nesse estudo utilizou-se a integração ensino-serviço que tem sido na efetividade das práticas do SUS um cenário de aprendizagem para os discentes, docentes e profissionais. Essa integração possibilita novas formas de organização do trabalho em saúde a partir do relacionamento interdisciplinar, da troca de experiências e de conhecimento entre as partes além, de contribuir com a qualidade, desenvolvimento da instituição e satisfação em produções deixadas para o serviço de saúde ${ }^{(13)}$.

Assim, esse estudo objetiva apresentar o produto gerado na experiência de integração ensino-serviço para o mapeamento e análise do fluxo de 
medicamentos que suprem uma Unidade de Pronto Atendimento (UPA) pública no intuito de apresentar possíveis melhorias ao serviço.

\section{MATERIAL E MÉTODOS}

Trata-se de um relato de experiência construído na articulação do Escritório de Qualidade para Organizações de Saúde (EsQualOS), programa de extensão da Universidade do Estado de Mato Grosso, com a gestão administrativa dos serviços de atenção terciária do Sistema Único de Saúde (SUS) em Tangará da Serra - MT.

No ano de 2016 houve a entrega de uma nova infraestrutura dos serviços de atenção terciária no município de Tangará da Serra - MT que reconfigurou as instalações de forma integrada a um complexo hospitalar que abrange a Unidade de Pronto Atendimento (UPA), Hospital Municipal Arlete Daisy Chichetti de Brito e a o Serviço de Atendimento Móvel de Urgência (SAMU) Decreto $n^{\circ} 216$, de 30 de junho de $2016^{(14)}$. A partir dessa estrutura 0 EsQualOS obteve, através das parcerias de extensão e pesquisa, uma sala de trabalho que objetiva apoiar a integração ensino-serviço nas demandas priorizadas por esses serviços, e constituir-se como espaço de trabalho para reunião e estudo dos profissionais, docentes e alunos dos cursos de enfermagem e administração.

A ampliação da estrutura física da atenção terciária e a necessidade de adaptação inicial dos serviços preocupavam a gestão e coordenações técnicas desse complexo. Foi solicitado pelos gestores do hospital, no ano de 2017, que o EsQualOS, por possuir uma equipe interprofissional e integrar profissionais desse complexo como membros, apoiasse na construção de instrumentos normativos, tais como, manual de normas e rotinas e procedimentos operacional padrão além de desenhos de fluxogramas de atendimentos, o que possibilitaria fazer uma análise do fluxo, dado a inexistência desses documentos.

Das prioridades definidas nas reuniões o processo de distribuição de medicamentos foi o elegível para rápido mapeamento, especificamente, a dispensação da farmácia para a UPA, uma vez que a farmácia do hospital é a responsável pela distribuição dos medicamentos à UPA.

A grupo de trabalho formado integrou profissionais da UPA e da farmácia, docentes do curso de administração e enfermagem e discentes dos respectivos cursos que são bolsistas do EsQualOS. A escolha do mapeamento foi considerada uma importante etapa no processo de gestão, por definir atividades-chave, medidas de desempenho, identificar oportunidades de melhoria, propor treinamento quando necessário, monitorar e visualizar como as atividades se concretizam e se interrelacionam ${ }^{(15)}$.

Para mapear os processos definiram-se dois momentos: o primeiro construiu o desenho de fluxo dos medicamentos e o levantamento de documentos. Essa etapa constou de reuniões com os profissionais envolvidos, médicos, 
enfermeiros, técnicos de enfermagem, farmacêutico, administrativo que totalizou três encontros com duração média de duas horas. O segundo constou de acompanhamentos através do checklist de cada macroprocesso elaborado nas reuniões. A verificação na prática foi realizada pelo coordenador do projeto e dois bolsistas nos setores da farmácia e da UPA, com realização de dez visitas e duração de seis horas em cada, no intuito de conferir se todas as informações haviam sido mapeadas nas reuniões. As visitas foram finalizadas a partir do momento que não se apresentou nenhuma alteração a mais nas informações coletadas.

Os dados adquiridos na primeira e segunda fase compuseram um banco de dados que delineou as principais atividades do fluxo de medicamentos, que foi transferido para o Software Microsoft Visio 2010, no intuito de delinear o fluxograma do macroprocesso dos medicamentos. A construção do fluxograma teve por finalidade evidenciar, nas diferentes etapas do processo, as competências que são requeridas pelos setores e pelos profissionais de saúde no intuito de efetivar uma construção de práticas assistenciais em saúde que estejam consonantes com a proposta do SUS.

O delineamento do "fluxo de medicamentos da farmácia do hospital para a UPA", no modelo descritivo e fluxograma, foi analisado com as normatizações das diretrizes preconizadas no documento de Assistência Farmacêutica: Gerência Técnica de Assistência Farmacêutica(12) que apresenta o fluxo de medicamentos desde o recebimento, armazenamento, conservação, distribuição e controle e direcionou na construção de um quadro comparativo, como plano de melhoria indicada à direção.

A construção dessas fases propiciou como produto um relatório sobre pontos de melhorias no processo do fluxo de medicamentos para a gestão hospitalar e o desenho do fluxo.

\section{RESULTADOS E DISCUSSÃO}

A estrutura da UPA é composta por: uma recepção, posto de atendimento, três consultórios médicos, sala de classificação de risco, sala da ouvidoria, semiintensiva, sala de observação masculina e uma feminina com quatro leitos disponíveis cada, box de emergência com dois leitos, sala de gesso e sala de eletrocardiograma, sendo que não havia uma farmácia, motivo que responsabiliza a farmácia do hospital.

Identificou-se no fluxo de medicamentos da farmácia do hospital para a UPA os processos: recebimento, armazenamento, conservação, distribuição e controle, e sua execução acontece conforme especificado no Quadro 1.

Quadro 1. Processos de recebimento, armazenamento, conservação, distribuição e controle para uma unidade de pronto atendimento pública. 


\begin{tabular}{|c|c|}
\hline $\begin{array}{l}\text { RECEBIMENTO NA } \\
\text { FARMÁCIA }\end{array}$ & $\begin{array}{l}\text { A área da farmácia possui um local para recepção e descarga dos } \\
\text { medicamentos localizada no interior do hospital. A entrada desses } \\
\text { medicamentos na farmácia é realizada por uma porta com acesso } \\
\text { externo (evitando que os medicamentos transitem por dentro do } \\
\text { hospital). Os medicamentos chegam em caixas de papelão e } \\
\text { identificados, a auxiliar de farmácia posiciona-os em cima de paletes } \\
\text { de madeira evitando que fiquem em contato direto com o piso. A } \\
\text { auxiliar de farmácia realiza a conferência de: nomes dos } \\
\text { medicamentos, marca, lotes, validade do medicamento, quantidade } \\
\text { de caixas, unidades e qualidade dos medicamentos, anotando todos } \\
\text { esses dados em uma folha por escrito manualmente, subprocesso } \\
\text { que dura cerca de duas horas, realizado semanalmente conforme a } \\
\text { demanda do hospital. } \\
\text { Depois de realizada a conferência, a auxiliar de farmácia lança as } \\
\text { quantidades de cada medicamento recebido no Sistema de } \\
\text { Informação G-MUS da farmácia, as quantidades devem ser idênticas } \\
\text { às lançadas pela Central de Abastecimento Farmacêutico (CAF), no } \\
\text { momento do despacho dos medicamentos do almoxarifado da } \\
\text { Prefeitura Municipal, condição para que seja efetuada a entrada dos } \\
\text { medicamentos no sistema. O farmacêutico supervisiona as } \\
\text { quantidades lançadas no sistema, e a CAF envia um documento } \\
\text { impresso e pelo site G-MUS denominado Mapa Cego de } \\
\text { Transferência, informando o que foi encaminhado para a farmácia. }\end{array}$ \\
\hline $\begin{array}{l}\text { ARMAZENAMENTO } \\
\text { NA FARMÁCIA }\end{array}$ & $\begin{array}{l}\text { O auxiliar de farmácia depois que realiza a conferência do } \\
\text { recebimento, acomoda os medicamentos na sala de armazenamento } \\
\text { que possui sistema de ar condicionado com temperatura ( } 20 \text { a } 23^{\circ} \\
\mathrm{C}) \text {, para o acondicionamento dos medicamentos. Os medicamentos } \\
\text { termolábeis possui uma geladeira com temperatura de } 2 \text { a } 8^{\circ} \mathrm{C} \text {. A } \\
\text { disposição dos medicamentos obedece à organização em ordem } \\
\text { alfabética pelo nome genérico; e em categorias: eletrólitos, gotas, } \\
\text { injetáveis, ampolas, pomadas, frascos, suspensões e xaropes. } \\
\\
\text { Os medicamentos são mantidos nas próprias caixas de embalagem, } \\
\text { com exceção dos: em gotas, suspensões e xaropes que são } \\
\text { armazenados em unidades fora da sua caixa de embalagem. Todos } \\
\text { ficam expostos em prateleiras de forma organizada: os } \\
\text { medicamentos com data de validade mais próxima ficam na frente } \\
\text { para que sejam retirados primeiro. Medicamentos controlados e } \\
\text { antibióticos ficam armazenados em um armário de aço fechado e } \\
\text { trancado com chave. Os Medicamentos vencidos, lacres violados e } \\
\text { embalagens danificadas são separados pelo farmacêutico e/ou } \\
\text { auxiliar de farmácia, embalados, identificados e é realizada baixa no } \\
\text { estoque pelo sistema G-MUS, solicitando recolhimento pela Máxima } \\
\text { Ambiental. }\end{array}$ \\
\hline $\begin{array}{l}\text { CONSERVAÇÃO } \\
\text { FARMACIA }\end{array}$ & $\begin{array}{l}\text { Os medicamentos armazenados são conservados em temperatura } \\
\text { de } 20 \text { a } 23^{\circ} \mathrm{C} \text { por ar condicionado, os medicamentos termolábeis } \\
\text { como por exemplo: o propofol, atracúrio, albumina, insulina regular } \\
\mathrm{NPH} \text {, matergan (imunoglobulina anti } \mathrm{RH} \text { ), anfotericina B são } \\
\text { mantidas em uma geladeira de } 2 \text { a } 8^{\circ} \mathrm{C} \text { de temperatura. }\end{array}$ \\
\hline
\end{tabular}




\begin{tabular}{|c|c|}
\hline $\begin{array}{l}\text { DISTRIBUIÇÃO DA } \\
\text { FARMÁCIA PARA } \\
\text { A UPA }\end{array}$ & $\begin{array}{l}\text { A distribuição para reposição de medicamentos no Posto de } \\
\text { Atendimento na UPA ocorre quando os técnicos de enfermagem } \\
\text { verificam a falta dos medicamentos e os anotam por escrito em papel } \\
\text { comum, e o encaminha à farmácia para solicitação. No caso de } \\
\text { solicitação de medicamentos que não constam no posto, os técnicos } \\
\text { de enfermagem levam junto as prescrições médicas (PM) em mãos } \\
\text { (contendo código do prontuário, nome do paciente, nome do médico, } \\
\text { assinatura do profissional). Para os medicamentos controlados e } \\
\text { antibióticos a solicitação é por meio da prescrição médica (PM) e } \\
\text { receita controlada (RC) para o auxiliar de farmácia, logo a auxiliar de } \\
\text { farmácia pega os medicamentos solicitados e entrega ao técnico de } \\
\text { enfermagem }\end{array}$ \\
\hline $\begin{array}{l}\text { CONTROLE } \\
\text { NA FARMÁCIA }\end{array}$ & $\begin{array}{l}\text { É realizado pelo auxiliar de farmácia e às vezes pelo farmacêutico } \\
\text { dependendo da demanda, através da supervisão das receitas } \\
\text { (código da receita, nome do paciente, e nome do médico) logo que } \\
\text { ocorre, o lançamento da saída de medicamentos pelo sistema } \\
\text { informatizado G-MUS, na própria farmácia. Na farmácia, o auxiliar de } \\
\text { farmácia realiza a saída dos medicamentos lançando os dados no } \\
\text { caderno (setor, quantidade, descrição do medicamento, código do } \\
\text { paciente, nome do médico, junto com a assinatura do profissional } \\
\text { que solicitou) e depois lança no sistema informatizado G-MUS (cada } \\
\text { auxiliar de farmácia possui senha no sistema para realizar a saída). } \\
\text { Os medicamentos que possuem sistema diferenciado de saída são: } \\
\text { os controlados e antibióticos para os quais o lançamento da saída é } \\
\text { feito manualmente em um livro registro de saída (LRS), pois não } \\
\text { possui sistema informatizado. Os medicamentos antibióticos e } \\
\text { controlados possuem outro livro com termo de abertura (LTA) } \\
\text { específico, integrado com as receitas controladas (RC) originais. A } \\
\text { farmacêutica anota todos os medicamentos controlados no livro } \\
\text { Termo de Abertura (Portaria nº } 344 \text { de } 12 / 05 / 98) \text { e guarda as RC } \\
\text { originais em anexo. Contudo, todos os medicamentos que são } \\
\text { distribuídos para o setor da Unidade de Pronto Atendimento a } \\
\text { farmácia levam à saída de estoque no sistema. }\end{array}$ \\
\hline $\begin{array}{l}\text { DISPOSIÇÃO NA } \\
\text { UPA }\end{array}$ & $\begin{array}{l}\text { Ao final desses processos os medicamentos solicitados para a UPA } \\
\text { ficam dispostos no Posto de Atendimento. Para os medicamentos } \\
\text { controlados e antibióticos há uma caixa lacrada; para os termolábeis } \\
\text { uma geladeira e para os outros tipos de medicamentos em armário e } \\
\text { gaveta, identificados com nomes em cada repartição específica. }\end{array}$ \\
\hline
\end{tabular}

No processo de recebimento na farmácia, conforme exposto no Quadro 1, observou retrabalho no ponto da execução da conferência dos medicamentos recebidos, pois o profissional precisa anotar manualmente a conferência dos medicamentos para posteriormente lançar no sistema de informação os dados de recebimento.

Em tempo de informatização, rápido acesso e otimização do trabalho, sistemas de informatização são necessários e a implementação de checklist informatizado para conferência dos medicamentos integrado com os sistemas de gerenciamento no recebimento proporciona rapidez no trabalho do profissional, além de garantir as informações necessárias para este processo como: quantidades corretas, etiquetagem dos medicamentos para controle de 
movimentação, incluindo lote e validade, marca do medicamento, e se possível medicamento identificado via de código de barras ${ }^{(16-17)}$.

Os medicamentos são armazenados conforme a possibilidade da estrutura existente. Percebe-se que há tentativas de atender às instruções específicas do fabricante e as demais exigências da legislação vigente como a temperatura, forma de armazenar e luminosidade, porém nota-se na organização dos medicamentos que não há identificação nas prateleiras com o nome específico de suas categorias e/ou nome dos medicamentos, o que dificulta o momento da separação de um medicamento.

A disposição dos medicamentos deve estar organizada de forma que sua localização seja dinâmica, rápida e eficiente e a identificação da localização dos medicamentos na sala possibilite agilidade na retirada dos medicamentos solicitados o que reduzirá possibilidade de erro e, consequentemente, de retrabalho no armazenamento ${ }^{(17-18)}$.

No processo de conservação dos medicamentos observou-se que não há registro diário de conferência de temperatura do ambiente. Existem diversos fatores intrínsecos e extrínsecos provocados por condição ambiental que são perdidos quando há inexistência do controle de temperatura dos medicamentos que pode causar alterações e deteriorações como reações químicas que refletem na decomposição e eficácia ${ }^{(12)}$. A falta de controle de temperatura gera perda de medicamentos, causa prejuízos de recursos financeiros e, se chegar ao paciente, corre risco de reação alérgica e progressão à morte por intoxicação(9).

No processo de distribuição observou que na UPA não há solicitação de medicamentos para a farmácia informatizada, sendo que não uma farmácia satélite, é necessário deslocamento à farmácia central do hospital, que atua como mantenedora para suprir a demanda dos setores do Hospital e da UPA. Durante as visitas, nas observações foi cronometrado o tempo que se leva para os profissionais transitarem da UPA até a farmácia do hospital que totalizou um deslocamento mínimo de 1 minuto e 32 segundos, o que reforçou ao grupo de trabalho a importância no controle dos medicamentos como ponto de melhoria.

A ausência de uma farmácia satélite na UPA os processos de recebimentos, armazenamento, conservação, distribuição e controle ficam a cargo dos profissionais, conforme a demanda de paciente. Um estudo ${ }^{(19)}$ que analisou farmácias satélites pontuou que os principais objetivos dessas farmácias são de manter uma logística de receber, armazenar, conservar, distribuir e controlar adequadamente os medicamentos, com rapidez e agilidade no processo de distribuição, além de favorecer no tempo dispendido do profissional e a busca do medicamento desejado.

No processo de controle observou que a partir do momento da distribuição e saída da farmácia, os medicamentos dispostos na UPA perdem o processo de controle, ou seja, a quantidade de medicamentos utilizados e administrados não possui registro, anotação ou sistema de saída. Caso haja conferência é necessário busca nos prontuários. Essa situação tem sido uma das preocupações dos coordenadores tanto por falhas no controle de estoque 
como no controle de gastos. Foi constatado que o hospital conta com uma rede de sistema informatizado, porém os dados lançados no sistema não possuem consolidação para fornecimento de informações no final do processo de controle dos medicamentos.

Subsidiar a programação de controle de medicamentos visa à manutenção dos níveis de estoques como entrada e saída direcionada à necessidade do atendimento da demanda, evita-se a superposição de estoques ou desabastecimento do sistema ${ }^{(12)}$. Um sistema informatizado, fácil e integrado, no qual os medicamentos prescritos são lançados e imediatamente enviados ao sistema da farmácia pode promover a racionalização dos recursos e proporcionar melhoria da qualidade do atendimento e facilidade no acompanhamento logístico do fluxo de medicamentos ${ }^{(16)}$.

A análise do fluxo foi possível identificar à luz do referencial(12) dez pontos de melhorias, após mapeamento, descrição e análise do fluxo. As melhorias na gestão de fluxo estão apresentadas no Quadro 2.

Quadro 2. Melhorias sugeridas para cada processo do fluxo de recebimento, armazenamento, conservação, distribuição e controle de medicamentos para suprir a UPA, no sudoeste do estado de Mato Grosso, pelo grupo de trabalho em 2017.

\begin{tabular}{|c|c|c|c|}
\hline $\begin{array}{l}\text { PROCESSO } \\
\text { ANALISADO NO } \\
\text { FLUXO }\end{array}$ & $\begin{array}{l}\text { MACRO } \\
\text { PROBLEMA } \\
\text { ENCONTRADO }\end{array}$ & $\begin{array}{l}\text { JUSTIFICATIVA DO } \\
\text { MACRO PROBLEMA } \\
\text { (BRASIL, 2006) }\end{array}$ & $\begin{array}{l}\text { PROPOSTA DE } \\
\text { MELHORIA } \\
\text { PARA O OBJETO } \\
\text { ESTUDADO }\end{array}$ \\
\hline $\begin{array}{l}\text { RECEBIMENTO } \\
\text { NA FARMÁCIA }\end{array}$ & $\begin{array}{l}\text { Não } \\
\text { informatização de } \\
\text { conferência do } \\
\text { recebimento dos } \\
\text { medicamentos na } \\
\text { farmácia. } \\
\\
\text { O tempo } \\
\text { dispendido do } \\
\text { profissional em } \\
\text { anotar } \\
\text { manualmente a } \\
\text { conferência dos } \\
\text { medicamentos e } \\
\text { depois ter que } \\
\text { lançar para o } \\
\text { Sistema G-MUS. }\end{array}$ & $\begin{array}{l}\text { Na entrada do } \\
\text { medicamento no } \\
\text { sistema operacional de } \\
\text { gerenciamento de } \\
\text { estoques, dos produtos } \\
\text { recebidos via leitores de } \\
\text { código de barras ou } \\
\text { equipamentos } \\
\text { conectados on-line com } \\
\text { o sistema, } \\
\text { disponibilizando o } \\
\text { material de forma } \\
\text { segura para uso } \\
\text { imediato ou solicitação } \\
\text { imediata das unidades } \\
\text { componentes da rede } \\
\text { pública de saúde. Este } \\
\text { sistema de controle } \\
\text { proporciona rapidez no } \\
\text { trabalho do profissional } \\
\text { além de garantir as } \\
\text { informações } \\
\text { necessárias. }\end{array}$ & $\begin{array}{l}\text { Elaborar um checklist de } \\
\text { medicamentos para } \\
\text { conferência do recebimento } \\
\text { em sistema informatizado, } \\
\text { contendo: nomes dos } \\
\text { medicamentos, marca, } \\
\text { lotes, validade do } \\
\text { medicamento, quantidade } \\
\text { de caixas, unidades e } \\
\text { qualidade dos } \\
\text { medicamentos. } \\
\text { Solicitar e integrar } \\
\text { equipamentos para rotular } \\
\text { medicamentos via leitores } \\
\text { de código de barras, com o } \\
\text { objetivo de ler o código, } \\
\text { identificar o medicamento } \\
\text { para ter controle de } \\
\text { estoque (entrada e saída) } \\
\text { no sistema G-MUS. }\end{array}$ \\
\hline
\end{tabular}




\begin{tabular}{|c|c|c|c|}
\hline $\begin{array}{l}\text { ARMAZENAMEN } \\
\text { TO NA } \\
\text { FARMÁCIA }\end{array}$ & $\begin{array}{l}\text { Não há } \\
\text { identificação nas } \\
\text { prateleiras, } \\
\text { armários e } \\
\text { geladeira com o } \\
\text { nome específico } \\
\text { das categorias } \\
\text { e/ou nome dos } \\
\text { medicamentos. }\end{array}$ & $\begin{array}{l}\text { No armazenamento } \\
\text { consiste em ordenar, } \\
\text { organizar, identificar } \\
\text { adequadamente os } \\
\text { produtos em áreas } \\
\text { apropriadas, de acordo } \\
\text { com suas } \\
\text { características e } \\
\text { condições de } \\
\text { conservação exigidas } \\
\text { (termolábeis, } \\
\text { psicofármacos, } \\
\text { inflamáveis, material } \\
\text { médico-hospitalar etc.). }\end{array}$ & $\begin{array}{l}\text { Elaborar identificação e } \\
\text { sinalização dos } \\
\text { medicamentos de forma } \\
\text { que permita fácil } \\
\text { visualização, agilizar sua } \\
\text { localização para sua } \\
\text { distribuição e reposição, } \\
\text { reduzindo erros e } \\
\text { retrabalho, facilitando sua } \\
\text { retirada. }\end{array}$ \\
\hline $\begin{array}{l}\text { CONSERVAÇÃO } \\
\text { NA FARMÁCIA }\end{array}$ & $\begin{array}{l}\text { Não há Registro } \\
\text { de Controle Diário } \\
\text { de temperatura. }\end{array}$ & $\begin{array}{l}\text { Conservar } \\
\text { medicamentos em } \\
\text { temperatura adequada é } \\
\text { manter os produtos em } \\
\text { condições satisfatórias } \\
\text { de estocagem para } \\
\text { manutenção de sua } \\
\text { estabilidade e } \\
\text { integridade durante o } \\
\text { período de vida útil. } \\
\text { Para o controle da } \\
\text { temperatura, é } \\
\text { necessária a utilização } \\
\text { de termômetros nas } \\
\text { áreas de estocagem, } \\
\text { com registros diários em } \\
\text { mapa de controle e } \\
\text { registro. }\end{array}$ & $\begin{array}{l}\text { Elaborar e implementar um } \\
\text { Livro de Registro de } \\
\text { Controle Diário de } \\
\text { temperatura, para verificar } \\
\text { com os padrões de } \\
\text { checagem e conferência. }\end{array}$ \\
\hline $\begin{array}{l}\text { DISTRIBUIÇÃO } \\
\text { DA FARMÁCIA } \\
\text { PARA UPA }\end{array}$ & $\begin{array}{l}\text { Não há lista } \\
\text { informatizada } \\
\text { para solicitação } \\
\text { de medicamentos } \\
\text { na UPA. } \\
\text { Necessidade de } \\
\text { haver uma } \\
\text { farmácia satélite. } \\
\text { Não há horário } \\
\text { fixo para realizar } \\
\text { a distribuição dos } \\
\text { medicamentos } \\
\text { para a UPA. }\end{array}$ & $\begin{array}{l}\text { Uma distribuição } \\
\text { informatizada, horários } \\
\text { fixos de medicamentos } \\
\text { devem garantir: rapidez } \\
\text { e segurança na entrega, } \\
\text { e eficiência no sistema } \\
\text { de informação e } \\
\text { controle. Farmácia } \\
\text { Satélite integrada a UPA } \\
\text { garante uma logística } \\
\text { hospitalar, com rapidez } \\
\text { e agilidade no processo } \\
\text { de distribuição, além de } \\
\text { favorecer no tempo } \\
\text { dispendido do } \\
\text { profissional a busca do } \\
\text { medicamento desejado. }\end{array}$ & $\begin{array}{l}\text { Elaborar um checklist } \\
\text { informatizado para } \\
\text { solicitação dos } \\
\text { medicamentos da UPA } \\
\text { para a farmácia, contendo: } \\
\text { nome dos medicamentos e } \\
\text { quantidades. } \\
\text { Implantar uma farmácia } \\
\text { satélite na Unidade de } \\
\text { Pronto Atendimento. }\end{array}$ \\
\hline
\end{tabular}




\begin{tabular}{|c|c|c|c|}
\hline $\begin{array}{l}\text { OPÇÃO } \\
\text { SUGERIDA } \\
\text { CASO NÃO } \\
\text { SEJA POSSÍVEL } \\
\text { IMPLANTAR } \\
\text { UMA FARMÁCIA } \\
\text { SATÉLITE NA } \\
\text { UPA }\end{array}$ & $\begin{array}{l}\text { Não possui os } \\
\text { processos de } \\
\text { recebimento, } \\
\text { armazenamento, } \\
\text { conservação, } \\
\text { distribuição e } \\
\text { controle na UPA. }\end{array}$ & $\begin{array}{l}\text { Adequar um fluxo } \\
\text { contínuo pode garantir a } \\
\text { qualidade e eficácia dos } \\
\text { medicamentos vindos } \\
\text { da farmácia, além de } \\
\text { integrar sistema de } \\
\text { controle, rapidez no } \\
\text { trabalho do profissional } \\
\text { e qualidade a } \\
\text { assistência ao paciente. }\end{array}$ & $\begin{array}{l}\text { Elaborar um checklist } \\
\text { informatizado para } \\
\text { solicitação dos } \\
\text { medicamentos da UPA } \\
\text { para a farmácia, contendo: } \\
\text { nome dos medicamentos e } \\
\text { quantidades. } \\
\text { Estabelecer horários fixos } \\
\text { para solicitação dos } \\
\text { medicamentos para } \\
\text { reposição na UPA. } \\
\text { Solicitar mobílias para } \\
\text { melhor armazenamento } \\
\text { dos medicamentos na } \\
\text { UPA. } \\
\text { Elaborar e implementar um } \\
\text { Livro de Registro de } \\
\text { Controle Diário de } \\
\text { temperatura, para } \\
\text { verificação de acordo com } \\
\text { os padrões de checagem e } \\
\text { conferência. } \\
\text { Implementar um Livro de } \\
\text { Registro de Saída para os } \\
\text { medicamentos na UPA, } \\
\text { contendo: nome do } \\
\text { medicamento, quantidade, } \\
\text { nome do médico, junto com } \\
\text { a assinatura do } \\
\text { responsável. } \\
\text { Elaborar e implementar um } \\
\text { Controle de sistema } \\
\text { informatizado, com } \\
\text { computadores para acesso } \\
\text { ao sistema G-MUS com } \\
\text { intuito de lançar entrada e } \\
\text { saída dos medicamentos } \\
\text { utilizados na UPA. }\end{array}$ \\
\hline
\end{tabular}




\begin{tabular}{|c|c|c|c|}
\hline $\begin{array}{l}\text { CONTROLE DA } \\
\text { FARMÁCIA } \\
\text { PARA A } \\
\text { UNIDADE DE } \\
\text { PRONTO } \\
\text { ATENDIMENTO }\end{array}$ & $\begin{array}{l}\text { A Unidade de } \\
\text { Pronto } \\
\text { Atendimento não } \\
\text { possui controle de } \\
\text { saída dos } \\
\text { medicamentos. } \\
\text { Não há sistema } \\
\text { de informações } \\
\text { para saída dos } \\
\text { medicamentos na } \\
\text { Unidade de } \\
\text { Pronto } \\
\text { Atendimento. }\end{array}$ & $\begin{array}{l}\text { Atividade técnico- } \\
\text { administrativa que tem } \\
\text { por objetivo subsidiar a } \\
\text { programação de } \\
\text { controle de } \\
\text { medicamentos, visando } \\
\text { à manutenção dos } \\
\text { níveis de estoques } \\
\text { como entrada e saída } \\
\text { necessários ao } \\
\text { atendimento da } \\
\text { demanda, evitando-se a } \\
\text { superposição de } \\
\text { estoques ou } \\
\text { desabastecimento do } \\
\text { sistema. }\end{array}$ & $\begin{array}{l}\text { Implantar o controle de } \\
\text { sistema informatizado de } \\
\text { entrada e saída dos } \\
\text { medicamentos utilizados na } \\
\text { unidade de pronto } \\
\text { atendimento. } \\
\text { Integrar os sistemas e } \\
\text { consolidar os dados entre } \\
\text { os setores, havendo assim } \\
\text { o controle das saídas dos } \\
\text { medicamentos na Unidade } \\
\text { de Pronto Atendimento. }\end{array}$ \\
\hline
\end{tabular}

Identificou que as ações de trabalho dos profissionais acabam por ser isoladas e resulta em uma fragmentação do cuidado que não é analisada ou controlada, colocando em risco a segurança do paciente. Frente às diretrizes da Organização Mundial da Saúde e do Ministério da Saúde a falta do acompanhamento, em longo prazo, dos processos que envolvem a distribuição de medicamentos acaba por distanciar cada vez mais os trabalhadores de avaliação e monitoramento do seu processo de trabalho.

A adoção de modernos controles de dispensação de medicamento contribui desta forma para a segurança do paciente e dos profissionais envolvidos no processo do cuidado, sendo que essa é uma tendência de modernização intrínseca na evolução do ambiente hospitalar ${ }^{(20)}$.

No registro desse mapeamento identificou o modelo de gestão hospitalar tradicional caracterizado pelo predomínio de funções verticais. Esse tipo de modelo é característico dos serviços de saúde, principalmente hospitalares com grande influência da administração clássica de Taylor e Fayol, induzidos por amplo poder concentrado nas diretorias e pouca articulação com a base operacional de trabalho. Tal posição preocupou o grupo de trabalho por entender que o fluxo de medicamento é um dos insumos transversais na equipe multiprofissional e que necessita de uma comunicação efetiva entre os diferentes departamentos.

Por fim, há necessidade de instituir na organização o monitoramento e avaliação do fluxo de medicamentos como formas de induzirem a compreensão melhor do fluxo e a melhor análise situacional de cada etapa, no intuito de buscar estratégias de minimização de erros e gastos, o que resulta na sustentabilidade do Sistema Único de Saúde, frente às demandas contemporâneas e de estrita restrição orçamentária, além de colocar em pauta a questão da qualidade nos processos de saúde desse processo mapeado.

\section{CONSIDERAÇÕES FINAIS}


Esse relato de experiência revelou pouca atenção no planejamento logístico referente aos processos de medicamentos e as potencialidades que podem interferir na qualidade do serviço de saúde. As observações e análise do fluxo de medicamentos revelaram problemas com relação ao recebimento, armazenamento, conservação, distribuição e controle dos medicamentos, porém há em cada processo a possibilidade de melhoria em curto e longo prazo.

As condições mapeadas nesse estudo podem contribuir para o aperfeiçoamento dos processos gerenciais. Ao construir o fluxo de medicamentos e propor melhorias este trabalho revelou a necessidade de elaborar instrumentos informatizados que requere menor custo financeiro e de curto prazo para execução. Outras propostas sugeridas como a reestruturação organizacional, bem como a instalação de uma farmácia satélite para o serviço na UPA demandam longo prazo, recursos humanos e financeiros para execução.

Na perspectiva de um cuidado com qualidade e integral o mapeamento de processos pode auxiliar a gestão na compreensão de seus processos e da prática de suas ações assistenciais. A pouca publicação de estudos que mapeiam o suprimento de medicamentos em instituições de saúde, a inexistência na instituição de protocolos, manuais, normas e rotinas exigiu desse grupo de trabalho maior tempo despendido na construção do fluxo. Essa experiência contribui para o campo de conhecimento local e produziu, internamente, no serviço novas necessidades de mapeamento.

Conclui-se que o movimento dado na integração ensino-serviço por ações da articulação interprofissional do EsQualOS mostra um importante campo de aproximação dos trabalhadores para uma função de gestão colaborativa e inicia um diálogo interno para possíveis mudanças no modelo de gestão, pois há uma participação do serviço no processo de reflexão de suas práticas e na construção do relatório final, auferindo corresponsabilidade a todos os atores envolvidos.

\section{REFERÊNCIAS}

1. Velloso MCM, et al. Gestão do conhecimento aplicado a serviços hospitalares: um estudo empírico em um hospital privado. FACEF Pesquisa: Desenvolvimento e Gestão, v. 18, n. 2 - p. 149-166 - mai/jun/jul/ago 2015. Disponível em: http://periodicos.unifacef.com.br/index.php/facefpesquisa/article/viewFile/10 $\underline{16 / 789}$

2. La Forgia GM, Couttolenc BF. Desempenho hospitalar no Brasil: em busca da excelência. São Paulo: Singular, 2009. 
3. Queiroz ACS, Albuquerque LG, Malik AM. Gestão estratégica de pessoal e inovação: estudos de caso no contexto hospitalar. Revista de Administração (São Paulo) 2013; 48:658-70.

4. Brito LAL, Malik AM, Brito E, Bulgacov S, Andreassi T. Práticas de gestão em hospitais privados de médio porte em São Paulo, Brasil. Cad. Saúde Pública [Internet] 2017. Disponível em: http://www.scielo.br/pdf/csp/v33n3/1678-4464-csp-33-03-e00030715.pdf.

5. Ayres APS, Elia BS, Pinto GLA, Silva RB. Logística em organizações de saúde. Rio de Janeiro. Editora FGV, 2010.

6. Toigo AT, Piccoli MR, Facin CE. Orçamento como meio de controle da dissociação em Hospital Público. Revista de Contabilidade do Mestrado em Ciências Contábeis da UERJ (online), Rio de Janeiro, v. 21, n. 2, p. 52 - p. 66, maio/ago., 2016. ISSN 1984-3291.

7. Calliari G, Teixeira AV. A judicialização da saúde e a má distribuição de recursos para medicamentos de baixa escala e/ou alto custo. Revista Eletrônica Direito e Política. Programa de Pós-Graduação Stricto Sensu em Ciência Jurídica da UNIVALI, Itajaí, v. 12, n. 1, 1ํquadrimestre de 2017.

8. Barbieri CJ, Claude M. Logística Hospitalar: teoria e prática. São Paulo: Saraiva, 2009.

9. Moura LL, Silva RF, Filgueiras BAG, Correira JMS. Análise e intervenção na gestão do fluxo de informações de uma cadeia de suprimentos hospitalares. Revista Eletrônica Sistemas \& Gestão. Volume 8, Número 4, 2013, pp. 416-430 DOI: 10.7177/sg. 2013.v8.n4.a8.

10. Silva JASV, Hinrichsen SL, Brayner KAS, Vilella TAS, Lemos MC. et al. Glosas hospitalares e o uso de protocolos assistenciais: revisão integrativa da literatura. Rev. Adm. Saúde Vol. 17, № 66, Jan. - Mar. 2017. DOI: http://dx.doi.org/10.23973/ras.66.13.

11. Cenci T. Gestão De Processos Administrativos no Hospital beneficente Santa Terezinha [monografia na internet]. Lajeado. Centro Universitário Univates, 2015. Disponível em: https://www.univates.br/bdu/bitstream/10737/1029/1/2015TatianeCenci.pdf.

12. Brasil. Ministério da Saúde. Secretaria de Políticas de Saúde. Departamento de Atenção Básica. Gerência Técnica de Assistência Farmacêutica. Assistência farmacêutica na atenção básica: instruções técnicas para sua organização. Brasília; 2006.

13. Vasconcelos ACF, Stedefeldt E, Frutuoso MFP. Uma experiência de integração ensino-serviço e a mudança de práticas profissionais: com a palavra, os profissionais de saúde. Interface (Botucatu) [Internet]. 2016 Mar [cited 2018 July 19] ; 20 (56): 147-158. Available from: http://www.scielo.br/scielo.php?script=sci_arttext\&pid=S141432832016000100147\&lng=en. http://dx.doi.org/10.1590/1807$\underline{57622015.0395 .}$. 
14. Tangará da Serra (MT). Decreto ํㅡㄹ 216, de 30 de junho de 2016. Institui o complexo hospitalar municipal. Diário Oficial de Tangará da Serra (Mato Grosso). 05 de julho de 2016.

15. Müller CJ. Modelo de gestão integrando planejamento estratégico, sistemas de avaliação de desempenho e gerenciamento de processo (MEIO-Modelo de Estratégia, Indicadores e Operações). [Tese]. Porto Alegre: Universidade Federal do Rio Grande do Sul; 2003.

16. Coêlho EPF. Logística De Dispensação Na Rede De Saúde Pública. III Congresso Consad de Gestão Pública, Painel 08/030 Experiências inovadoras em gestão de suprimentos. 15-17 março de 2010. Brasília-DF. Brasil.

17. Velozo, CCP. Armazenagem e Movimentação de medicamentos no Município de Apiaí [monografia na internet]. Universidade Tecnológica Federal Do Paraná, Departamento Acadêmico de Gestão e Economia, Curso de especialização em Gestão Pública Municipal. Curitiba. Paraná: 2011. Disponível em: http://repositorio.roca.utfpr.edu.br/jspui/bitstream/1/1137/1/CT GPM I 2011 12.PDF.

18. Blatt CR, Campos CMT, Becker IRT. Gestão da Assistência Farmacêutica. Modulo 4, Unidade 3: Programação, aquisição, armazenamento e distribuição de medicamentos. Universidade Federal de Santa Catarina, Curso de Gestão da Assistência Farmacêutica Especialização à distância, Universidade Aberta do SUS. Florianópolis: Ed. da UFSC, 2011.

19. Nakamura ACR, Piedade LFS, Tozi LA, Sousa VJ. Estudo de Sistema de Dispensação de Medicamentos para administração nos pacientes da ala de internação. Fatec. São José dos Campos, 2012.

20. Paulo CHO. Dispensação e distribuição de medicamentos do Serviço Farmacêutico em um hospital universitário. RAS Vol. 16, № 62 - Jan-Mar, 2014. DOI: $10.5327 / Z 1519-1672201400620003$.

Recebido: 28 de agosto de 2018. Publicado: 28 de setembro de 2018

Correspondência: Josué Souza Gleriano. E-mail: josuegleriano@unemat.br

Conflito de Interesses: os autores declararam não haver conflito de interesses. 
(C) This is an Open Access article distributed under the terms of the Creative Commons Attribution License, which permits unrestricted use, distribution, and reproduction in any medium, provided the original work is properly cited 